\title{
Rhaphidotrema kiatkiongi, a new genus and species of blood fluke (Digenea: Aporocotylidae) from Arothron hispidus (Osteichthyes: Tetraodontidae) from the Great Barrier Reef, Australia
}

\author{
Russell Q.Y. Yong and Thomas H. Cribb
}

\author{
School of Biological Sciences, The University of Queensland, Brisbane, Queensland 4072, Australia
}

\begin{abstract}
A new genus of fish blood flukes (Aporocotylidae Odhner, 1912) is proposed for a species found on reefs surrounding Lizard Island on the northern Great Barrier Reef. Rhaphidotrema kiatkiongi gen. et sp. n. was recovered from the heart of the starsand-stripes pufferfish, Arothron hispidus (L.) (Tetraodontidae). Rhaphidotrema kiatkiongi is notable as the first digenean reported to possess a penis stylet. It also differs from all other aporocotylid flukes in having a combination of 18-19 testes in a group at the ends of the intestinal caeca, a broad lanceolate body shape with a dextrally-directed posterior bend at the level of the male genital pore, and separate genital pores, with the female genital pore distinctly sinistral and the male genital pore slightly dextral to midline. This is the second species of aporocotylid fluke reported from this pufferfish.
\end{abstract}

Keywords: Aporocotylidae, Rhaphidotrema, Arothron hispidus, Tetraodontidae, new genus, Great Barrier Reef

In an analysis of the pattern of the discovery of trematode genera, Cribb and Bray (2011) reported evidence that the Aporocotylidae was the least well-known family of trematodes, on the basis that new genera are being reported for it faster than for any other family. In that analysis to 2008, eight of the 29 recognised genera had been reported since 2000 (Bullard and Overstreet 2003, Nolan and Cribb 2004a, b, 2005, 2006a, b, Bullard and Jensen 2008, Bullard et al. 2008). Since then, the pace of discovery has continued unabated, with the recent proposal of Littorellicola Bullard, 2010 and Skoulekia AlamaBermejo, Montero, Raga et Holzer, 2011 (Bullard 2010, Alama-Bermejo et al. 2011). Here we present evidence for another new aporocotylid genus.

In May 2009, two stars-and-stripes pufferfish, Arothron hispidus (L). (Tetraodontidae) were collected off Lizard Island on the northern Great Barrier Reef (GBR). Examination of the hearts revealed infection by an unknown aporocotylid fluke, which proved to be a new species. Analysis of the morphology has led us to propose a new genus for this species.

\section{MATERIALS AND METHODS}

Two Arothron hispidus (TL 22.0 and $27.5 \mathrm{~cm}$ ) were speared off Lizard Island, GBR, Queensland, Australia. The fishes were brought back to the laboratory in 70-litre containers of seawater and were euthanised prior to dissection via cranial pithing. Upon death, the hearts were excised from the body and examined under a dissection microscope using fine scissors and forceps. Flukes were killed and heat fixed by being pipetted into
$0.85 \%$ saline just off the boil and transferred to Eppendorf tubes containing $10 \%$ formalin solution at room temperature (Cribb and Bray 2010). Flukes were stained using Mayer's haematoxylin, destained in $1 \%$ hydrochloric acid, neutralised in $1 \%$ ammonia solution, dehydrated in a graded series of ethanols, cleared in methyl salicylate and finally mounted in Canada balsam on glass slides. All drawings were made using a camera lucida, and all measurements, in micrometres, were made using a digital camera and the programme SPOT Advanced (version 4.6).

\section{RESULTS}

\section{Rhaphidotrema gen. n.}

Diagnosis. Body flattened, lanceolate, with dextral bend towards posterior end in region of genital pores. Tegumental spines in marginal transverse rows, continuous along length of body except for oral region and at level of male genital pore on both flanks. Spines minute, straight; thorn-shaped or fused spines lacking. Oral sucker absent. Mouth subterminal. Oesophagus long, sinuous, extending to midbody region. Caeca X-shaped; anterior caeca short, with short, broad lateral diverticula; posterior caeca long, strongly sinuous, extending to or just among testes. Testes 18-19 in number, irregularly shaped, generally oblong, surrounding posterior extremities of posterior caeca. Cirrus-sac absent. Seminal duct passes to right of ovary, passes along dextral margin of ovary before passing sinistrally dorsal to oviduct. Seminal vesicle elongate, terminates in a penis stylet. Both terminus of seminal tract and area immediately around base of penis stylet surrounded by dense spherical muscle. Sclerotised penis stylet long, 
slender, sharp-ended, begins medially, projects through genital pore. Male genital pore dorsal, slightly dextral to midline. Ovary median, entire, posterior to testes. Oötype just posterior to male genital pore. Oviduct entirely postovarian. Uterine coils relatively simple, initially directed posteriorly then anteriorly, entirely post-ovarian. Metraterm narrow, slightly sinistral, sinistrally directed. Female genital pore dorsal, distinctly sinistral to midline, anterior to male pore. Vitellarium follicular, in separate lateral fields anterior to caecal bifurcation, confluent medially posterior to caecal bifurcation, extends from near level of nerve commissure posteriorly to testes, does not extend laterally beyond lateral nerve cords. Excretory vesicle slender, vase-shaped with paired collecting ducts arising from anterolateral margins. Excretory pore terminal. Type species R. kiatkiongi sp. n.

Etymology: The generic name is derived from the Greek word for 'needle', 'rhaphidos', an allusion to the penis stylet of the type species, the first known for a digenean trematode, and 'trema' referring to its identity as a trematode.

\section{Rhaphidotrema kiatkiongi $\mathrm{sp} . \mathrm{n}$.}

Figs. 1-4

Description (based on 2 adult specimens): Body broadly lanceolate, with pronounced dextral bend close to posterior end, approximately 3.5 times longer than wide (Fig. 1), 3970-4178 (4074) × 1030-1300 (1165). Tegumental spines along body margin, encroaching medially $71-75$ dorsally and 76-79 ventrally $(n=10$ spine rows from 2 specimens), continuous along length of body except for oral region and two posterior regions, at area of male genital pore, and on flank directly opposite (indicated by arrows in Fig. 1). Each row with 18-22 spines; spines minute, straight, length 4 (Fig. 3). Thorn-shaped or fused spines lacking. Oral sucker absent. Mouth subterminal, 20-34 (27) from anterior body end. Oesophagus sinuous, $1578-1667$ (1623), or $37-42 \%$ (40\%) of body length. Caeca form X-shape; anterior caeca 353-474 in length; posterior caeca much longer than anterior, 10011361 in length. One adult specimen with only left posterior caecum present. Testes 18-19 in number, 106-181 $(145) \times 54-98(75)(\mathrm{n}=10$ testes from 2 specimens $)$, surrounding posterior ends of posterior caeca. Seminal duct passing along dextral ovarian margin before passing dorso-sinistrally to oviduct (Fig. 2). Seminal vesicle present, 174-194 (184) × 40-51 (46). Spherical muscular mass at base of penis stylet 78-80 (79) $\times 59-60(60)$. Male genital pore dorsal, slightly dextral to midline, 7-11 (9) wide, 70 from lateral border, 318-350 (334) from posterior extremity. Protrusible penis stylet prominent, 130-150 (140) in length, slender, sharp-ended, projects via male genital pore (Figs. 2, 4). Ovary entire, median, posterior to testes, 243-300 (272) × 177-220 (199). Oviduct entirely post-ovarian, with small loop posterior to ovarian boundary. Oötype just posterior to male genital pore. Uterine coils entirely post-ovarian, relatively simple, passing initially posteriorly, then anteriorly, ventral to male genitalia and around muscular mass at base of penis stylet. Metraterm post-ovarian, narrow, antero-sinistrally directed, passing ventral to seminal duct, 232-248 $(240) \times 47-63$ (55). Female genital pore dorsal, distinctly sinistral to midline, anterior and opposite to male pore, 93-120 (107) from lateral margin, 590-620 (605) from posterior extremity, 24-30 (27) in diameter. Vitellarium maximum length 1398-2570 (1984) and maximum width 593-775 (684). Vitelline duct passes initially parallel to seminal duct, dorsally then ventrally to oötype where it joins uterus. Excretory vesicle slender, vase-shaped with paired collecting ducts arising at anterolateral margins, $70 \times 10$. Primary collecting ducts visible only just anterior to excretory vesicle. Excretory pore terminal.

Juvenile (based on one specimen, with damage to anterior region - oral region obscured): Body 1720 long, 361 wide. Tegumental spination as in adult, also showing unspined regions at oral area, as well as in area of male genital pore and on flank directly opposite. Body margins noticeably more crimped than in adults. Oesophagus 1042 in length. Caeca long and sinuous, anterior caeca 298 and 313, posterior caeca 546 and 661 in length. Testes not developed. Ovary $90 \times 94$. Other aspects of reproductive system indistinct. Vitelline follicles visible, as in adult. Excretory system not apparent.

Egg: Seen in situ in preserved worms and trapped (probably as a transmission dead end) in heart tissue; one live egg observed in heart tissue containing miracidium. Egg an elongate spheroid, $35 \times 21$. Other eggs observed in heart tissue contained miracidia, cellular aggregations or were degenerate.

Type host: Arothron hispidus (L.) (Tetraodontiformes: Tetraodontidae), stars-and-stripes pufferfish.

Site in host: Luminal surface of bulbus arteriosus.

Prevalence and intensity: Two of two fish infected, one with three adult flukes, one with one immature fluke.

Ty p e 1 o c a 1 ity: Lizard Island, northern Great Barrier Reef, Queensland, Australia $\left(14^{\circ} 40^{\prime} 08^{\prime \prime} \mathrm{S}, 145^{\circ} 27^{\prime} 34^{\prime \prime} \mathrm{E}\right)$

Colle ct or s: T.H. Cribb, R.A. Bray.

Specimens deposited: Queensland Museum (Brisbane, Australia), holotype QM G233538, paratypes QM G233539, QM G233540 and QM G233541.

Etymology: The species name honours Mr. Yong Kiat Kiong, the grandfather of the senior author, as thanks for his endless guidance, support and wisdom.

Remarks. As discussed below, the outstanding feature of this species and genus is its possession of a penis stylet. The precise function of the components of the male terminal genitalia has not been elucidated but it appears likely that sperm is delivered via the narrow orifice of the stylet.

\section{DISCUSSION}

Morphological comparison of the present form with other genera of Aporocotylidae suggests that this species requires a new genus. Rhaphidotrema can be immediately distinguished through a combination of its prominent pro- 

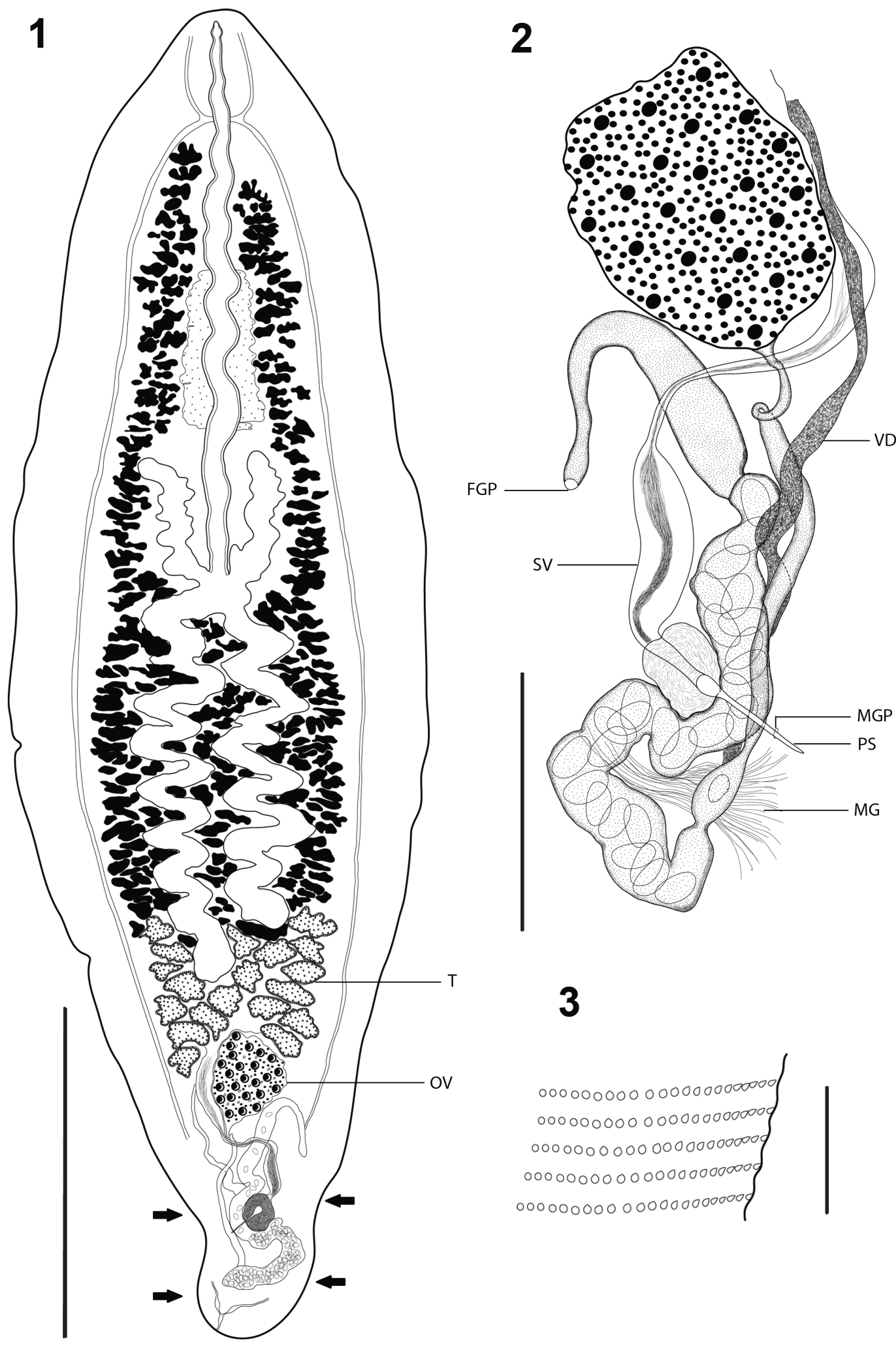

3

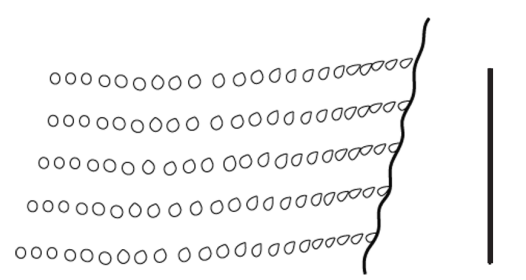

Figs. 1-3. Rhaphidotrema kiatkiongi sp. n. from heart of Arothron hispidus. Fig. 1. Holotype, whole animal, ventral view showing vitellaria in black, testes $(\mathrm{Tt})$ and ovary $(\mathrm{OV})$. Arrows show the points where the marginal spine rows stop and start. Fig. 2. Paratype, terminal genitalia, dorsal view showing the vitelline duct (VD), Mehlis' gland (MG), seminal vesicle (SV), both male (MGP) and female (FGP) genital pores and the protrusible penis stylet (PS). Fig. 3. Holotype, spination, showing ventral rows of $\sim 20$ minute, straight spines. Scale bars: Fig. $1=1000 \mu \mathrm{m}$; Fig. $2=200 \mu \mathrm{m}$; Fig. $3=50 \mu \mathrm{m}$. 


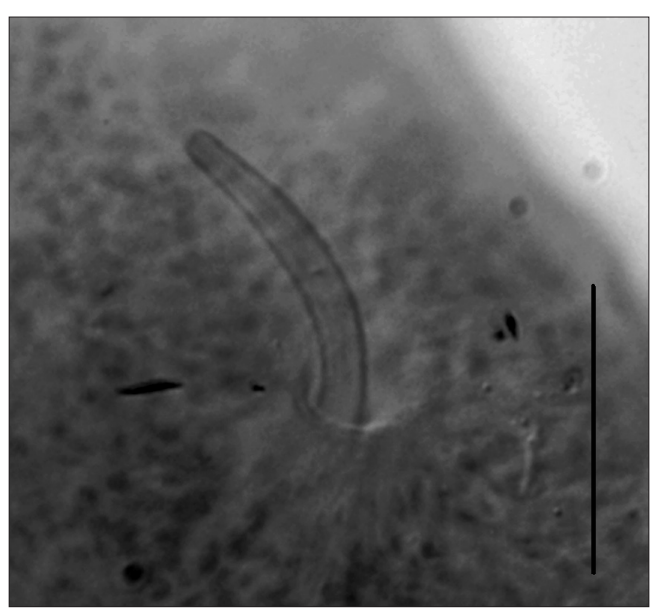

Fig. 4. Rhaphidotrema kiatkiongi sp. n. from heart of Arothron hispidus; micrograph showing the penis stylet protruding through the male genital pore. Scale bar $=50 \mu \mathrm{m}$.

trusible penis stylet, the arrangement of the testes, body shape and separate genital pores opening on different sides of the midline. Rhaphidotrema also differs from the other 29 presently-recognised genera through a combination of six characteristics considered useful for diagnosis at genus level: body shape, the absence of an oral sucker, the length of the caeca, the number and arrangement of the testes, the position of the genital pores, and the extent of the vitellarium.

Rhaphidotrema kiatkiongi has a sclerotised penis stylet which projects externally via the male genital pore. Trematodes have a wide range of organisation of terminal genitalia, including cirrus-sacs, hermaphroditic sacs, sinus-sacs, naked terminal ducts and various ornamentation of the genital pore; at least one family, the Microphallidae Ward, 1901 has species possessing a phallus which projects through the genital pore (Deblock 2002). We are, however, unaware of a penis stylet elsewhere in the class. The stylet of $R$. kiatkiongi is simple, sharp-ended, and lacking in armature, appearing analogous to the stylets present in some Monogenea and Turbellaria (Chisholm et al. 2001). This remarkable feature alone suggests that this form merits a new genus.

Rhaphidotrema kiatkiongi is also the only aporocotylid with a dextral bend to its posterior end. Neoparacardicola Yamaguti, 1970 has a similarly prominent posterior bend, but bends sinistrally rather than dextrally. In Neoparacardicola, this bend actually takes the form of a notch at which both reproductive systems terminate (Yamaguti 1970). Rhaphidotrema kiatkiongi hence differs from Neoparacardicola by not having the genital pores open at the position of the bend. Instead, the bend is at the level of the male genital pore. Rhaphidotrema kiatkiongi is notably in the minority of aporocotylids with separate genital pores; it is the only species whose male genital pore is positioned slightly dextral and female genital pore distinctly sinistral to midline. Species of most other genera of apo- rocotylids have either common genital pores or separate genital pores which open on the same sides of the body, with the exceptions of the following genera: Braya Nolan et Cribb, 2006 has medial male and sinistral female pores; Metaplehniella Lebedev et Parukhin, 1972 has sinistral male and medial female pores, both sinistrally directed; Paradeontacylix McIntosh, 1934, and Psettarium Goto et Ozaki, 1930, both have sinistral male and medial female genital pores.

The presence of 18-19 testes in Rhaphidotrema and their arrangement immediately distinguish it from all but the six genera whose species have multiple testes: Acipensericola Bullard, Snyder, Jensen et Overstreet, 2008, Aporocotyle Odhner, 1900, Littorellicola Bullard, 2010, Paradeontacylix McIntosh, 1934, Plethorchis Martin, 1975, and Pseudocardicola Parukhin, 1985. The clustering of testes at the ends of the posterior caeca is unique to Rhaphidotrema. Additionally, Rhaphidotrema can be immediately distinguished from Acipensericola and Littorellicola through its lack of an oral sucker. It is distinguished from Aporocotyle through a combination of body shape (broadly lanceolate with a bent posterior end, instead of elongate-lanceolate), having its tegumental spines arranged in incomplete ventro-lateral transverse rows instead of ventro-marginal clusters, the relatively longer oesophagus extending into the midbody (37-42\% total body length) and the post-caecal, rather than intercaecal testes. Rhaphidotrema differs from Paradeontacylix through a combination of a broad rather than a slender elongate-lanceolate body, not having large tegumental spines that decrease in number per row approaching the extremities, and the post-caecal rather than mostly intercaecal position of the testes. Plethorchis is immediately distinguishable from Rhaphidotrema through a combination of its long, ribbon-like body shape, rudimentary anterior caeca, the extent of the vitellarium from the oesophagus to the uterus (as opposed to from the dorsal nerve commissure to anterior to the testes in Rhaphidotrema), as well as infection site and host; Plethorchis infects mesenteric vessels in the body cavity of a mugiliform, the gray mullet, Mugil cephalus, whereas Rhaphidotrema infects the lumen of the bulbus arteriosus of a tetraodontiform. Rhaphidotrema differs from Pseudocardicola in body shape (broadly lanceolate as opposed to slender) and in having 18-19 irregularly-shaped testes in a postcaecal arrangement, as opposed to five irregularly circular testes arranged intercaecally along the body midline.

Rhaphidotrema kiatkiongi is the second species of aporocotylid reported from the pufferfish Arothron hispidus after Paracardicola hawaiensis Martin, 1960, and the seventh overall from the Tetraodontidae. Other aporocotylid species known from tetraodontid fishes are Paradeontacylix sinensis Liu, 1997 from Chinese lattice pufferfish Takifugu oblongus, P. odhneri McIntosh, 1934 from purple pufferfish Takifugu porphyreus, Psettarium tropicum Manter, 1940 from bullseye pufferfish Spheroides 
oblongus, P. japonicum Goto et Ozaki, 1930 from panther and Japanese pufferfish (Takifugu pardalis and T. rubripes, respectively), and Psettarium sp. from T. rubripes in China and Japan (Ogawa et al. 2007). These reports are mainly the results of studies of infections in commercially harvested or aquacultured fish (e.g. Ogawa et al. 2007), and with the exceptions of Paracardicola hawaiensis and Psettarium tropicum, initially described from San Francisco, Ecuador (Manter 1940), all these discoveries have been made from temperate waters. From this pattern of discovery it seems likely that the tetraodontids have been undersurveyed for blood flukes. The Aporocotylidae can be considered the most poorly-understood family of trematodes (Cribb and Bray 2011), and with so many tropical species, the Tetraodontidae is potentially a source of significant undiscovered aporocotylid richness.
Acknowledgements. This study was supported by, and is a contribution from, the Australian node of the CReefs global research initiative (grant number: 209/29), a partnership between the Australian Biological Resource Study (ABRS), BHP Billiton, the Great Barrier Reef Foundation, the Census of Marine Life and the Australian Institute of Marine Science (AIMS). The CReefs Australia Project is generously sponsored by BHP Billiton in partnership with The Great Barrier Reef Foundation, the Australian Institute of Marine Science, the Australian Biological Resources Study and the Alfred P. Sloan Foundation. CReefs is a field program of the Census of Marine Life. This study was also supported by United States NSF-REVSYS grant DEB1051106. We thank Dr. Rodney Bray for his aid in obtaining specimens for this study, and Dr. Terrence Miller for comments on an earlier version of this manuscript. Lastly, we thank the staff of the Lizard Island Research Station, for their practical and enthusiastic support of our research.

\section{REFERENCES}

Alama-Bermejo G., Montero F.E., Raga J.A., Holzer A.S. 2011: Skoulekia meningialis n. gen., n. sp. (Digenea: Aporocotylidae Odhner, 1912) a parasite surrounding the brain of the Mediterranean common two-banded seabream Diplodus vulgaris (Geoffrey Saint-Hilaire, 1817) (Teleostei: Sparidae): description, molecular phylogeny, habitat and pathology. Parasitol. Int. 60: 34-44.

Bullard S.A. 2010: Littorellicola billhawkinsi n. gen., n. sp. (Digenea: Aporocotylidae) from the myocardial lacunae of Florida pompano, Trachinotus carolinus (Carangidae) in the Gulf of Mexico; with a comment on the interrelationships and functional morphology of intertrabecular aporocotylids. Parasitol. Int. 59: 587-598.

Bullard S.A., Jensen K. 2008: Blood flukes (Digenea: Aporocotylidae) of stingrays (Myliobatiformes: Dasyatidae): $O r-$ chispirium heterovitellatum from Himantura imbricata in the Bay of Bengal and a new genus and species of Aporocotylidae from Dasyatis sabina in the northern Gulf of Mexico. J. Parasitol. 94: 1311-1321.

Bullard S.A., Overstreet R.M. 2003: Elaphrobates euzeti gen. and sp. n. (Digenea: Sanguinicolidae) from snappers (Lutjanidae) in the Gulf of Mexico. In: C. Combes and J. Jourdan (Eds.), Taxonomy, Ecology and Evolution of Metazoan Parasites. PUP, Perpignan, France, pp. 97-113.

Bullard S.A., Snyder S.D., Jensen K., Overstreet R.M. 2008: New genus and species of Aporocotylidae (Digenea) from a basal actinopterygian, the American paddlefish, Polyodon spathula (Acipenseriformes: Polyodontidae) from the Mississippi Delta. J. Parasitol. 94: 487-495.

Chisholm L.A., Whittington I.D., Kearn G.C. 2001: Dendromonocotyle colorni sp. n. (Monogenea: Monocotylidae) from the skin of Himantura uarnak (Dasyatididae) from Israel and a new host record for D. octodiscus from the Bahamas. Folia Parasitol. 48: 15-20.

CRibB T.H., Bray R.A. 2010: Gut wash, body soak, blender and heat fixation: approaches to the effective collection, fixation

Received 3 April 2011 and preservation of trematodes of fishes. Syst. Parasitol. 76: $1-7$.

CribB T.H., Bray R.A. 2011: Trematode families and genera: have we found them all? Trends Parasitol. 27: 149-154.

Deblock S. 2002: Family Microphallidae Ward, 1901. In: R.A. Bray, D.I. Gibson and A. Jones (Eds.), Keys to the Trematoda, Vol. 3. CAB International, Wallingford, pp. 151-192.

Manter H.W. 1940: Digenetic trematodes of fishes from the Galapagos Islands and the neighbouring Pacific. Rep. Allan Hancock Pac. Exped. 2: 329-497.

Martin W.E. 1960: Hawaiian Helminths. IV. Paracardicola hawaiensis n. gen., n. sp. (Trematoda: Sanguinicolidae) from the Balloon Fish, Tetraodon hispidus L. J. Parasitol. 46: 648-650.

Nolan M.J., CribB T.H. 2004a: Ankistromeces mariae n. g., n. sp. (Digenea: Sanguinicolidae) from Meuschenia freycineti (Monacanthidae) off Tasmania. Syst. Parasitol. 57: 151-157.

Nolan M.J., CribB T.H. 2004b: Two new blood flukes (Digenea: Sanguinicolidae) from Epinephelinae (Perciformes: Serranidae) of the Pacific Ocean. Parasitol. Int. 53: 327-335.

Nolan M.J., CribB T.H. 2005: Chaulioleptos haywardi n. gen., n. sp. (Digenea: Sanguinicolidae) from Filimanus heptadactyla (Perciformes: Polynemidae) of Moreton Bay, Australia. J. Parasitol. 91: 630-634.

Nolan M.J., CribB T.H. 2006a: Cardicola Short, 1953 and Braya n. gen. (Digenea: Sanguinicolidae) from five families of tropical Indo-Pacific fishes. Zootaxa 1265: 1-80.

Nolan M.J., CribB T.H. 2006b: An exceptionally rich complex of Sanguinicolidae von Graff, 1907 (Platyhelminthes: Trematoda) from Siganidae, Labridae and Mullidae (Teleostei: Perciformes) from the Indo-west Pacific Region. Zootaxa 1218: $1-80$.

Ogawa K., Nagano T., Akai N., Sugita A., Hall K.A. 2007: Blood fluke infection of cultured tiger puffer Takifugu rubripes imported from China to Japan. Fish Pathol. 42: 91-99.

Yamaguti S. 1970: Digenetic trematodes of Hawaiian fishes. Keigaku Publishing Co., Tokyo, 436 pp. 